\title{
(Mis)Understanding Sufferers with Rare Health Problems
}

\author{
Sarah Elizabeth Rich ${ }^{1 *}$ \\ ${ }^{1}$ Colby College, USA \\ *Corresponding Author: serich0913@gmail.com
}

Citation: Rich, S.E. (2016) (Mis)Understanding Sufferers with Rare Health Problems, European Journal of Sociology and Anthropology, 1:2 (2016), 1. doi:10.20897/ejsa.201601

Received: September 28, 2016; Accepted: November 23, 2016; Published: December 25, 2016

\begin{abstract}
The Constitution of the World Health Organization in conjunction with the United Nation's Declaration of Human Rights Article 2 declare that health is a human right no matter a person's background or sociostatus. I would like to suggest that "biological condition" be included with race, religion, political belief, economic and social condition because it is culturally constructed like these other categorizations. Numerous studies are conducted on how race, religion, and socio-economic position can lead to marginalization from the biomedical field. However, it is often overlooked how one's biological condition can lead to similar exclusion. Ethnographic research was conducted through field study and personal interviews. Supporting research was found through secondary sources. The way society and the medical field (mis)understand us continues to be highly problematic. Doctors, patients, and society must acknowledge the myth that Western biomedicine is omniscient in order to minimize the marginalization of sufferers of rare health problems. The pain caused by cultural marginalization can be as equally debilitating as the biological disease itself. If we can deconstruct this marginalization and reimagine a new way of addressing rare health conditions, then those afflicted by these illnesses will suffer a great deal less.
\end{abstract}

Keywords: medical anthropology, rare diseases, structural violence, global health, public health

\section{INTRODUCTION}

The enjoyment of the highest attainable standard of health is one of the fundamental rights of every human being without distinction of race, religion, political belief, economic or social condition.

\section{WHO, 2013}

The Constitution of the World Health Organization in conjunction with the United Nation's Declaration of Human Rights Article 2 declare that health is a human right no matter a person's background or socio-status. I would like to suggest that "biological condition" be included with race, religion, political belief, economic and social condition because it is culturally constructed like these other categorizations. Numerous studies are conducted on how race, religion, and socio-economic position can lead to marginalization from the biomedical field. However, it is often overlooked how one's biological condition can lead to similar exclusion. If health is a universal human right, then why is it being withheld from patients with rare health problems solely due to the uncommonness of their condition?

Through my experience with Behcet's, an autoimmune disease, I have found that falling outside of a normal medical diagnosis leads to feelings of further marginalization. According to the Behcet's Syndrome Society, "Patients with rare diseases are the orphans of health systems, often without diagnosis, without treatment, without research, and therefore without reason to hope" (Behcet's Syndrome Center, 2013). If the medical field and society 
at large can better understand these patients, then their reason to hope can be restored. Through my research, I strive to restore this hope by explaining why and how these sufferers experience marginalization.

How have growing technologies in modern biomedicine led to such certainty in diagnosing some diseases while leaving other rare diseases in a largely antiquated state? What are the consequences for and experiences of people who do not fit the "norm" dictated by modern, western medicine? And, what types of newly imagined communities have been created as a result of the relegation of these patients? These questions have driven my research as I seek to convey the reality of sufferers of rare and undiagnosed health problems.

According to Laurie Edwards (2013), health author and sufferer of a myriad of rare diseases, "culture informs the experience of illness, and living with illness ultimately shapes culture". The way society and the medical field treat people with these conditions dictates the experiences they have in conjunction with their biological suffering. Additionally, illness shapes culture; common diseases have catalyzed research and pushed technologies while simultaneously constructing a cultural understanding of what illness looks like.

Manderson and Smith-Morris (2010) acknowledge this cultural construction in their description of chronic illnesses, "These conditions neither develop nor continue in a vacuum, but are profoundly shaped by persistent injustice, inequality, poverty, and physical expressions of structural violence". The cultural construction of the "normal" way to be sick is also problematic considering that, "there is no single way to suffer; there is no timeless or spaceless universal shape to suffering" (Kleinman and Kleinman, 1996). Rare diseases fall outside of these technologies and cultural understandings and their sufferers are further marginalized. In retaliation against this phenomenon, undiagnosed and uncommon patients have found new ways to shape culture by creating newly imagined communities. By drawing upon my own experiences with illness, I seek to explain these questions and themes as they play out for the marginalized.

\section{MY VIGNETTE}

As I mentioned, I have Behcet's. A year ago, I was diagnosed with this rare, chronic, non-communicable autoimmune disease. Although I saw countless doctors of numerous specialties to determine the cause of my illness, it took seven years to reach a diagnosis due to the broad and various presentations of symptoms and the minimal awareness of the disease. I missed a fourth of my high school career due to flare-ups. I was miserable, detached, and rarely saw my friends because I was so sick. I also could no longer play soccer or field hockey, two loves of my life.

Despite the profound effects my illness had on my everyday life, no one could understand what was wrong with me. Some doctors and people in my community claimed I was making up my illness because they had not yet been able to scientifically diagnose my disease. At first, I was relieved to hear I had Behcet's, to finally know what was "wrong with me" and to be able to give my ailments a name. I thought that by putting a name to my illness, I could finally make people understand what I was going through. But, I soon learned that getting diagnosed did not mean speedy relief of the pain I have had to live with for so long. Not only is there little awareness of Behcet's, but also there is minimal research behind it and little funding for its treatment. I have now spent the year trying different treatments to put the disease in remission to no avail. All of these medications were originally engineered for other immune-affecting diseases from Malaria to Lupus to cancer. There is no clear-cut treatment and no medications specifically designed for the disease. Furthermore, Behcet's is incurable. So far, I have found little improvement along with severe side effects with the less than scientific, trial-and-error approach to treatment.

Despite the rarity of my disease and the severity of my circumstances, I am not unique. My story is common among Behcet's patients and other sufferers of rare and undiagnosed illnesses.

\section{(MIS)UNDERSTANDINGS}

\section{The Medical Community's Response}

Despite my experience of misunderstanding and marginalization, the medical community continues to disregard those of us who fall outside a commonly understood diagnosis. Over the years, modernization and advancing technologies have further polarized the experiences of the diagnosable and the unknown (Manderson and SmithMorris, 2010). According to Edwards (2013), "We now find ourselves at an intersection, lodged between the promise of science and technology and lingering assumptions about people who are forced to dwell in the kingdom of the sick". Rare and undiagnosed sufferers are left in limbo while biomedical technologies assume omniscience despite enduring gaps in understanding of Behcet's and other mysterious ailments. As Jim Young Kim et al. (2000) point out in the book Dying for Growth, there is no reason that some diseases should still be marginalized and misunderstood when health gains are perceived to be exponentially improving with the unprecedented wealth and technological innovations available in the world today. 
The lack of research on Behcet's is largely responsible for the seven years it took to diagnosis me. Even after being diagnosed, I have had to suffer through a whole slew of medications that made me sicker rather than healthier. If scientists understood more about the disease, if pharmaceutical engineers took the time to develop a medication specific to Behcet's, and if doctors were more aware of the illness, than my experience with my illness would be drastically different and exponentially improved.

There is so little understanding behind Behcet's that even the name is under dispute. Some claim that it should be called "Behcet's Syndrome," as syndromes are defined as a collection of signs and symptoms known to frequently appear together without a known cause. Others argue that using the word "syndrome" is problematic because it belittles the severity of the illness. Instead, "Behcet's Disease" is often used to suggest the morbidity and clearly identifiable symptoms that define the illness.

This discrepancy is reminiscent of the start of HIV/AIDs epidemic when scientist lacked a consensual name for the disease. Gallo referred to his discovery as "the AIDS virus" with the proper name buman T-cell lenkemia virus, type III (HTLV-III). Meanwhile the Pasteur Institute named it "LAV" for lymphadenopatby virus. As a result, scientist often used the name HTLV-III/LAV (or LAV/HTLV-III). According to Treichler (1999), "The slash helped mark the virus's identity as culturally constructed and disputed". Five years after the discovery, the Human Retrovirus Sub-committee of the International Committee of the Taxonomy of Viruses compromised with the name HIV. As Treichler points out, the name HIV/AIDS is a consequence of a social dispute and cultural disagreement. The same is true with Behcet's with a name continually under dispute, not because of the biology of the disease, but rather because of the cultural (mis)understanding of it. If scientists cannot come to a consensus about the name of an illness, then how are patients supposed to understand their identity as it is constructed by that illness, and how is society supposed to understand patients who can't even describe what illness they have?

Despite the lack of consensus regarding HIV/AIDS in the 80's, there has since been a wealth of awareness raised about the disease that has helped dismantle many of the cultural misconceptions surrounding the condition. This movement sought to minimize stigmatization, promote testing and discloser, and open up discussion of HIV in order to greatly reduce misconceptions of the disease (Manderson and Smith-Morris, 2010). The change in cultural understanding over time and the argument over the name of HIV goes to show how culturally affected diseases may be, even big-name diseases like HIV/AIDS. The HIV/AIDS awareness movement serves as inspiration for rare diseases like Behcet's; there is hope that one day our culture can deconstruct their misconceptions about rare diseases and sufferers will no longer feel as stigmatized as they do today.

As many academics have pointed out, socioeconomic position can have a great impact on the type of medical care the patient encounters; but, in my case, it is not my personal financial status that yields the quality of health care I receive. Rather, it is the amount of money worldwide dedicated towards the research and awareness of the disease that results in the quality of treatment its sufferers receive. Behcet's effects predominately young adults and is most prevalently found in eastern Mediterranean countries, the Middle East, and the eastern Asian rim along the historic "silk road." These demographics suggest lower income levels and higher poverty rates, which make it difficult for patients to globally fund research for the disease. Furthermore, 17 out of 100,000 people are diagnosed with Behcet's in Turkey; 17 per 100,000 in Japan, Korea and China; 3 per 100,000 in Europe; and 6.6 per 100,000 in the United States (ABDA, 2013). These staggering statistics speak to the true rarity of the disease. The fact is, when Behcet's proportionally affects so few people, there is little incentive for scientists, pharmaceutical companies, and doctors to invest in researching the disease.

The ability for these medical actors to decide on the financial benefit they will reap for investing in research is deeply problematic given the resulting consequences for sufferers of rare health problems. Fassin refers to this phenomenon as the "politics of life," or the ability to give specific value and meaning to human life. Doctors, pharmaceutical companies, and even health insurance companies have the ability to value certain illness, and therefore certain people, over others. The lack of research behind Behcet's is indicative of the political and structural decisions that are made to value more financially rewarding diseases over others. This political power places these actors in a position that often leads to Paul Farmer's notion of "structural violence." Farmer discusses how social conditions determine who suffers and who are not based on inequalities, poverty, and power imbalance on a global scale. Although my case is not diffuse with racial, gender, or economic inequalities, it is clear that there is a power imbalance that creates an extra-marginalization of sufferers of rare and undiagnosed health problems. This imbalance is due solely to a person's biological condition.

As a result of these institutional problems and the lack of knowledge behind rare and undiagnosed ailments, doctors resort to treating symptoms rather than the cause of our illnesses. Although this may at times be a step towards ameliorating our conditions, it often results in the "hopelessness" referred to by the Behcet's Syndrome Society.

When I was sixteen years old, my gastroenterologist told me that I could live the rest of my life on a liquid diet. At this point, doctors understood that I suffered from chronic esophageal ulcers, but they were unaware that Behcet's caused these ulcers. Every time I swallowed, I felt excruciating pain, so I stopped eating even the broth 
and ice cream my mom tried to cox into me. It eventually got to the point that I could not even drink water because of the pain. I ended up in the emergency room for severe dehydration on multiple occasions. From then on, I was frequently hooked up to an IV to supply my body with the fluids and nutrients it needed. I also had a feeding tube put in that allowed me to inject liquid food directly into my stomach. When my doctor suggested that I could spend the rest of my life like this, I realized how problematic it was that the root of my illness was not being addressed.

I switched gastroenterologists and my new doctor referred me to the Pain Clinic at Children's Hospital. They too were intent on treating my symptoms rather than finding the cause of my pain. Perpetuating my inability to do school work, they prescribed me various narcotics. They also prescribed me Lyrica, which caused me to faint three times within fifteen minutes. It got to the point that the side effects were more debilitating than the pain I had grown accustom to. As the medicines continued to be insufficient in treating my pain, my doctor suggested prescribing me Phencyclidine (PCP). He suggested that I first take it inside his office since I might tear my skin off if I hallucinate, thinking there are bugs crawling inside me. The unpleasantness of this suggestion was enough to make me lose faith in the medical field altogether. Was this really the best option I could hope for to alleviate the illness I faced? Despite my adamant conclusion regarding the detriment of these drugs, many doctors continue to overlook the problematic concept of treating symptoms rather than searching for the cause.

Another trend I encountered was doctors' tendency to blame the patient when a biological reason for their issue did not present. Edwards (2013) experienced this and wrote, "If you cannot cure the patient, then blaming the patient often follows suit". I cannot count how many doctors suggested that my issues were psychosomatic. The pain clinic referred me to a psychiatrist. Despite his conclusion that I was "mentally stable," doctors continued to believe that I was "making up" my pain. Believe me, if I was playing make believe, I would not have come up with a story that isolated me from the activities and the people that I loved. It is easier for doctors to blame (perceived?) illnesses on psychiatric issues once they assume that they have ruled out all biological possibilities. In doing so, doctors presume their own omniscience; they cannot acknowledge the possibility that there still may be a biological reason for our suffering that they have overlooked or that may be under-researched or unknown. Instead they blame us, further perpetuating our marginalization.

\section{Society's Response Versus How I Understand My Condition}

In response to my negative experience with the western biomedical field, I sought help from alternative medicine. First, I saw a friend's mother who was an acupuncturist. Although I did not find relief through acupuncture, it was worth trying because it did not make me feel worse the way the pain clinic's approaches had. I then turned to a new treatment called "Muscle Activation Technique" (MAT). MAT is a physical therapy-like treatment crossed with neuromuscular science where the practitioner "evaluates the integrity of the neuromuscular system whenever a force has been applied against it" (MAT, 2013). The practitioner then stimulates the neuromuscular system by putting specific pressure to where the muscle connects to the bone. MAT was a godsend that allowed my body to strengthen so it could cope with the strain it went through due to my illness. Perhaps the best part of MAT was the fact that I did not need a diagnosis to receive treatment. Although biomedical tests could not explain what was wrong with me, my MAT practitioner was able to understand that my body was not "strong enough" and he made it so that my body could better combat my undiagnosed autoimmune disease by enhancing my neuromuscular function. I still use MAT today and it continues to help my body cope with the added stress of my Behcet's treatment. Ultimately, alternative medicine presented a much needed alternate route of treatment and it reinstalled hope that I could live a "normal" life. Alternative medicine was particularly beneficial route in my case because it rarely requires a diagnosis and it presented as a new option from the biomedical world that seemed to give up on me.

Alternative medicine helped quench my need for a diagnosis, however the medical field and society continue to put an emphasis on the importance of diagnoses. Because of the blame and misunderstanding I have encountered from western biomedical doctors, I continued to feel a personal need for a diagnosis. I had always believed that if I could only be diagnosed, then people would finally understand what I was going through. It has indeed been beneficial to finally put a name to my illness to an extent. For example, now when I tell a professor that I am sick and cannot finish an assignment or make it to class, I am no longer asked "Again?" with exasperation and disbelief. Because my professors know about my autoimmune disease, they are no longer surprised when I cannot make it to class. Being diagnosed has also made me feel as if I finally found a doctor who cared enough about me to figure out what was wrong. Oddly enough, having a diagnosis has really made a difference in how people react to me illness, even though the way I feel has not changed.

For sufferers of rare health problems, a diagnosis can be an odd experience due to the fact that the medical field and society's notions of our illnesses change drastically even though biologically nothing has changed for us. Receiving a diagnosis is also beneficial in convincing doctors and society that I am not "just making it up," it solidifies the realness of my disease. Somehow, not having a diagnosis renders a person as non-existent and invisible in the eyes of the medical field and our culture (Manderson and Smith-Morris, 2010). Therefore, a 
diagnosis renders a person visible to society. For me, this visibility is both beneficial as I have explained and negative because with a name, it is easier for my disease to define me and restrict me.

Although society may at times view me as "the women with Behcet's," this experience is a challenge that I can overcome. My adversity allows me to prove my strength and persistence to live a "normal" life. Unfortunately, it is our culture that dictates what it means to be "normal" and sufferers of rare health problems must reconstruct their own identities in order to understand where they fit within this construction.

Exclusion, fear, and hopelessness is not only caused by the way the medical field treats us, but also the response of society, separation from friends, and the inability to participate in certain activities. Even now that I have a diagnosis, my friends have ostracized me throughout the year because I have been debilitated by my trail-and-error treatment of Behcet's. Because I am sick so often, I am unable to spend time with my friends to the extent that I use to. In response, one of my friends sat me down and explained to me that she felt as if I no longer wanted to hang out with her because I was never around anymore. She expressed how she had placed me in a "new friend box" since she knew I would not be the type of friend who would go out with her any more. This misunderstanding was particularly hurtful coming from a close friend who in the past has always been there for me and understood where I was coming from. It is hard enough to deal with an incurable disease like Behcet's, to then be shut out by friends and blamed for being antisocial makes the experience almost unbearable.

In addition to losing friendships over rare health problems, sufferers of rare illnesses are often forced to discontinue their hobbies, further excluding them from the life they use to know. Before Behcet's began to dictate aspects of my life, I played on a nationally sanctioned field hockey team called Futures that feeds into the U.S. Olympic team. My dreams of competing in the Olympics or even winning the State Championship with my high school team were crushed when I had to give up on my sport due to my illness. During my senior year of high school, I sat on the cold metal bleachers and watched as my old team lost in overtime at the semi-qualifying game for the state championship. After the last goal, a previous teammate's mom leaned over to me and whispered, "They really need you on defense out there..." She trailed off and the buzzer rang. My teammates gathered on the field in a teary huddle while I walked out of the stadium alone, disconnected, and helpless.

Three years later, as a junior, I tried out for my college's field hockey team. Despite my ability to keep up with each player, my clear stick skills, and my innate field sense, the coach cut me from the team. She said, "Don't get me wrong, you're as good as any of my girls on the field... but with your health issues, you're a liability that I just can't deal with." I was disappointed to say the least. But this disappointment was not in my lack of ability, but rather in society's inability to understand my condition. I continue to hold my head high as a talented athlete, and many of the girls on the team admired me for my perseverance and positive attitude.

Despite the ostracizing and exclusionary effects of rare health problems, my ability to overcome this adversity has been a truly empowering experience. I have learned that if no one else (especially in the medical field) can help me, then at least I can help myself by staying positive. I believe that these experiences have changed who I am for the better; they have made me more understanding, sympathetic, and tolerant. A sense of exclusion paralleled with a sense of empowerment is a mark of the adversity caused by rare health problems.

\section{Cultural Construction}

In response to the marginalization we feel from society and the medical field alike, sufferers of rare health problems tend to band together and form an imagined community. I have been able to cultivate a strong relationship with numerous individuals who sufferer from rare health problems because they understand what I am going through and I understand what they are going through. Though they do not have Behcet's, their ailments range from Lyme disease to Celiac disease to entirely undiagnosed issues. These friends would never "put me in a new friend box" because they do not understand what I am going through. Similarly, I am able to help them through their illnesses because I know what it is like to go through what they are going thorugh. As Kleinman and Kleinman highlight, pain is incommunicable and it has the capacity to isolate sufferers and strip them of cultural resources, "Including especially the resource of language... to be in pain is to be certain about this knowledge. To be asked to react to another person's pain is to be in doubt about its existence" (Kleinman and Kleinman, 1996). Because we have all gone through similar experiences, it is as if we are speaking the same language and we can understand each other in ways our greater communities cannot.

Because of our shared experiences, we gravitate towards one another and create our own new community. According to Edwards (2013), "one of the greatest assets patients have in a healthy world [is] the solidarity of the illness experience". The important thing is to realize that no one is alone in this. No matter how rare the disease is, there are still a lot of people suffering from similar issues. The symptoms might not be the same, but there is a giant network of people like me.

These networks, or "imagined communities," that exist to support sufferers of rare health problems are not limited to the friendships I have described. For example, networks have grown out of the modernizing technology of Internet communities. Edwards (2013) notes, "it is only through technology that I have spoken to or met anyone 
else with my rare disease, PCD". I also have only interacted with someone with Behcet's via the Internet. Specifically, I have found support from the American Behcet's Disease Association's website (www.behcets.com) that consists of message boards, chat rooms, and other resources where sufferers of Behcet's can connect with one another and discuss their experience with the disease. Members of this community support each other and help one another cope with their disease. A similar website I have come across is called RareConnect. This site's mission statement is as follows: "RareConnect promotes global conversation and collaboration to improve the lives of rare disease patients and assists the organizations that serve them" (RareConnect, 2013). This website serves over 40 rare diseases ranging from Behcet's to Rett Syndrome to undiagnosed brain diseases. Benefits in joining include "connecting with others who understand and share your experiences" (RareConnect, 2013). This statement alludes to the fact that people who have gone through similar experiences are privileged to understand one another in a way that the broader global community cannot or does not understand.

Ultimately, technology and the Internet construct much needed imagined communities that offer support for sufferers who otherwise may feel alienated due to the rareness of their condition. In a sense, this outlet fights fire with fire. Despite growing technologies, our conditions cannot be detected, our illness may not be visible, and our physical pain is perpetuated; meanwhile we are now able to utilize other technologies like the Internet to ease our emotional pain. Therefore, modernization simultaneously causes and ameliorates our suffering.

\section{CONCLUSION}

It is clear that growing technologies in modern biomedicine have led to certainty in diagnosing some diseases while leaving others to be further marginalized. Consequences for and experiences of people who do not fit the norm dictated by modern biomedicine include exclusion, misunderstanding, frustration, and occasional hopelessness. At the same time, it has empowered us and taught us how to deal with adversity. These common experiences have bonded us and allowed us to form newly imagined communities.

As sufferers of rare health problems are subject to suffer from marginalization and misunderstanding from the medical community and society at large on top of our biological suffering, we construct newly imagined communities and find a sense of empowerment in order to ameliorate our experiences with illness. Despite our ability to construct a silver lining around our otherwise painful experiences, the way society and the medical field (mis)understand us continues to be highly problematic. Doctors, patients, and society must acknowledge the myth that Western biomedicine is omniscient. We must work to deconstruct this accepted truth in order to minimize the marginalization of sufferers of rare health problems. These individuals already suffer from so much biologically; they do not need the added strife of misunderstanding and exclusion they find today.

Unfortunately, I am unable to supply my readers with a clear-cut way of bettering our situation. However, creating awareness about our experiences and cultivating understanding is a step. The more doctors that approach their patients with cultural understanding rather than solely biological judgments, the better patients will feel. This approach is not a biological treatment, but rather an emotional one that is just as likely to better patient's experience with their disease as any medical treatment or drug prescription. The pain caused by cultural marginalization can be as equally debilitating as the biological disease itself. If we can deconstruct this marginalization and reimagine a new way of addressing rare health conditions, then those afflicted by these illnesses will suffer a great deal less.

\section{REFERENCES}

American Behcet's Disease Association. (2013). American Behcet's Disease Association. [online] Available at: http:/ /www.behcets.com/site/pp.asp?c=bhJIJSOCJrH\&b=260521 [Accessed 4 March 2013].

Behcet's Syndrome Center. (2013). Bebcet's Syndrome Society. [online] Available at: http://www.behcets.org.uk/menus/main.asp?PN=membership-whatthesocietydoes [Accessed 20 April 2013].

Edwards, L. (2013). In the Kingdom of the Sick: A Social History of Chronic Illness in America. New York: Walker \& Print. Farmer, P. (1996). On Suffering and Structural Violence: A View from Below. Daedalus, 125(1), pp. 261-283.

Kim, J.Y. (2000). Dying for Growth: Global Inequality and the Health of the Poor. Monroe, Me.: Common Courage. Print. Kleinman, A. and Kleinman, J. (1996). The Appeal of Experience; The Dismay of Images: Cultural Appropriations of Suffering in Our Times. Daedalus, 125(1), pp. 1-23.

Manderson, L. and Smith-Morris, C. (2010). Chronic Conditions, Fluid States: Chronicity and the Anthropology of Illness. New Brunswick: Rutgers UP. Print.

MAT. (2013). Muscle Activation Techniques. [online] Available at: http://www.muscleactivation.com/mat-overview/ [Accessed 10 May 2013]. 
RareConnect. (2013). RareConnect: Connecting Rare Disease Patients Globally. [online] Available at: https://www.rareconnect.org/en [Accessed 4 March 2013].

Treichler, P.A. (1999). How to Have Theory in an Epidemic: Cultural Chronicles of AIDS. Durham: Duke UP. Print.

World Health Organization. (2013). Constitution of The World Health Organization Forty-Fifth Edition. [online] Available at: http://www.who.int/governance/eb/who_constitution_en.pdf [Accessed 4 March 2013]. 